\title{
ASPECTOS DA VEGETAÇÃO ARBÓREA EM FRAGMENTO DE ESTEPE ESTACIONAL SAVANÍCOLA, BARRA DO QUARAÍ-RS, BRASIL
}

\author{
ARBOREAL VEGETATION ASPECTS ON A SEASONAL STEPPE SAVANNA REMAINING, \\ IN BARRA DO QUARAÍ, RS STATE, BRAZIL
}

\author{
Luciano Farinha Watzlawick ${ }^{1}$ Solon Jonas Longhi ${ }^{2}$ Paulo Renato Schneider ${ }^{3}$ \\ César Augusto Guimarães Finger ${ }^{4}$
}

\begin{abstract}
RESUMO
O presente estudo teve por objetivo avaliar a composição florística, a estrutura horizontal e vertical, bem como os padrões de distribuição espacial do componente arbóreo e agrupamento de espécies em uma amostra de Estepe Estacional Savanícola localizada no Parque do Espinilho, Barra do Quaraí - RS. Para o levantamento florístico e análise fitossociológica foi instalada, em uma área de ocorrência de Aspidosperma quebracho-blanco, uma unidade permanente de 4 ha $(200 \times 200 \mathrm{~m})$, onde todos os indivíduos com circunferência $(C) \geq 15,7 \mathrm{~cm}$ a $30 \mathrm{~cm}$ do nível do solo foram amostrados e medidas a circunferência e altura total. Foram encontrados 145 indivíduos/ha, distribuídos em 11 espécies, 10 gêneros e 8 famílias, com área basal de 4,06 m²/ha. A vegetação arbórea apresentou Índice de Diversidade de Shannon estimado em 1,86, sendo que as espécies com os maiores valores de importância foram Prosopis nigra (25,86\%), Aspidosperma quebracho-blanco (24,57\%), Prosopis affinis (24,30\%) e Vachellia caven (10,51\%), representando 85,26\% do total. A vegetação arbórea apresenta dois estratos bem definidos, o inferior com 93,3\% das árvores e o superior com apenas $6,7 \%$ do total de árvores amostradas. Neste a espécie Aspidosperma quebrachoblanco predomina com $70,0 \%$ das árvores. Com relação ao padrão de distribuição espacial das espécies, Aspidosperma quebracho-blanco apresentou tendência ao agrupamento, de acordo com o Índice de Payandeh, enquanto que as demais espécies apresentaram-se agrupadas. Aspidosperma quebracho-blanco e Prosopis nigra tendem a ocorrer associadas, enquanto Prosopis affinis e Vachellia caven formam grupos individuais. A associação estudada constitui-se de uma formação de espécies única no Brasil, apresentando questão de raridade em termos de composição de espécies e estrutura.
\end{abstract}

Palavras-chave: Parque do Espinilho; Prosopis; Aspidosperma quebracho-blanco; Vachellia caven.

\begin{abstract}
The purpose of this study was to evaluate the floristic composition, the horizontal and vertical structures, as well as the spatial distribution patterns of the tree component in a Steppe Savanna Park located at 'Parque do Espinilho', in Barra do Quaraí, Rio Grande do Sul state, Brazil. Floristic composition and phyto-sociological analysis were carried out in a four (04) ha permanent plot $\left(40000 \mathrm{~m}^{2}\right)$, where all individuals which circumference $(C)$ was $\geq 15.7 \mathrm{~cm}$, measured $30 \mathrm{~cm}$ from the ground, were sampled and had their circumference and total height measured. A mean of 145 individuals/ha was found, distributed in 11 species, 10 genera and eight (08) families, with basal area of $4.06 \mathrm{~m}^{2} / \mathrm{ha}$. The Shannon Diversity Index $\left(\mathrm{H}^{\prime}\right)$ for the tree vegetation was 1.86, and the species with the highest importance values were Prosopis nigra (25.86\%), Aspidosperma quebracho-blanco (24.57\%), Prosopis affinis (24.30\%) and Vachellia caven $(10.51 \%)$, representing $85.26 \%$ of the total. The tree vegetation has two strata, the lower one with

1 Engenheiro Florestal, Dr., Professor Associado do Departamento de Agronomia, Universidade Estadual do Centro-Oeste, Rua Salvador Renna com Padre Salvador, 875, Bairro Santa Cruz, CEP 85015-430, Guarapuava (PR), Brasil. luciano. watzlawick@pq.cnpq.br

2 Engenheiro Florestal, Dr., Professor Titular do Departamento de Ciências Florestais, Centro de Ciências Florestais, Universidade Federal de Santa Maria, Av. Roraima, 1000, CEP 97105-900, Santa Maria (RS), Brasil. solon.longhi@gmail.com

3 Engenheiro Florestal, Dr., Professor Titular do Departamento de Ciências Florestais, Centro de Ciências Florestais, Universidade Federal de Santa Maria, Av. Roraima, 1000, CEP 97105-900, Santa Maria (RS), Brasil. paulors@smail.ufsm.br

4 Engenheiro Florestal, Dr., Professor Associado do Departamento de Ciências Florestais, Centro de Ciências Florestais, Universidade Federal de Santa Maria, Av. Roraima, 1000, CEP 97105-900, Santa Maria (RS), Brasil. finger@smail.ufsm.br

Recebido para publicação em 13/11/2009 e aceito em 26/03/2013
\end{abstract}


93.3\% of the trees and the upper one with only $6.7 \%$ of total. The species Aspidosperma quebrachoblanco dominated with $70.0 \%$ of trees in this stratum. Regarding the spatial distribution pattern of the species, Aspidosperma quebracho-blanco presented a grouped tendency, whereas the other ones were grouped. The savannah steppe park studied is mainly characterized by the occurrence of Aspidosperma quebracho-blanco, Prosopis nigra, Prosopis affinis and Vachellia caven, constituting a unique combination of species in Brazil, presenting question of rarity in terms of species composition and structure. Keywords: Parque do Espinilho; Prosopis; Aspidosperma quebracho-blanco; Vachelia caven.

\section{INTRODUÇÃO}

No extremo meridional do Rio grande do Sul estendem-se amplas superfícies conservadas do Planalto da Campanha e da Depressão do Rio Ibicuí-Rio Negro, com relevo de aplainado a ondulado e dominância de solos derivados dos derrames basálticos e de diversas formações litológicas sedimentares. Revestindo estas feições geomorfológicas, desenvolvem-se formações campestres classificadas pelo Projeto RADAMBRASIL como Estepe. Corresponde à zona paleotropical cuja vegetação está submetida à dupla estacionalidade fisiológica, provocadas uma pelo frio e outra pela seca (VELOSO e GÓES FILHO, 1982).

No extremo oeste desta região localizase o "Parque Espinilho", caracterizado pela predominância da formação estépica. A primeira referência a esta vegetação foi realizada por Rambo (1956), o qual descreve como uma vegetação campestre que possui abundância de arbustos lenhosos, ou ainda espécies de porte arbóreo, as quais conferem à estepe um caráter de Parque.

A região do "Parque Espinilho" no Rio Grande do Sul é denominada por LEITE (1994), região da Estepe Estacional Savanícola. O conceito de Estepe Savanícola está associado ao xerofitismo. No extremo sudoeste do Estado, a fisionomia apresenta algumas particularidades. As características de estacionalidade climática são bem marcantes, com reflexos sensíveis na cobertura vegetal, que passa a comportar maior incidência de espécies espinhosas oriundas da região quente/seca chaqueana. Nota-se certa intensificação do calor, motivada, principalmente, pelas baixas altitudes associadas à continentalidade e redução comparativa da pluviosidade, na medida do afastamento das encostas do planalto e da costa leste. Podem ser citados outros fatores coadjuvantes para intensificação da inclemência do clima local. O principal deles é a penetração de frentes polares, com ventos mais frios e mais secos. Esta livre ação eólica intensifica os fenômenos de evapotranspiração das superfícies plano-onduladas e da própria cobertura vegetal. As temperaturas tendem a ser mais elevadas, com médias do mês mais quente (janeiro) de $24^{\circ} \mathrm{C}$ (até $26^{\circ} \mathrm{C}$ ) e máximas absolutas acima de $40{ }^{\circ} \mathrm{C}$ (até $42{ }^{\circ} \mathrm{C}$ ). O período frio (médias inferiores a $15{ }^{\circ} \mathrm{C}$ ) apesar de não muito intenso, como nas situações mais elevadas planaltinas, tem duração superior a três meses, com médias do mês mais frio (julho) entre 13 e $15^{\circ} \mathrm{C}$ e mínimas absolutas entre $-4{ }^{\circ} \mathrm{C}$ e $-8{ }^{\circ} \mathrm{C}$, com até dez noites frias (temperatura média menor ou igual a 0 ${ }^{\circ} \mathrm{C}$ ), durante o ano; frequentemente há formações de geadas (LEITE, 1994).

O manual da vegetação brasileira do IBGE (1992) descreve como uma vegetação situada na barra do rio Quaraí com o rio Uruguai constituindose como um exemplo clássico da Savana Estépica Parque, formado quase que exclusivamente por associações de Prosopis algarobilla (algarroba) e Acacia caven (espinilho), atualmente conhecidas, respectivamente, por Prosopis affinis Spreng. e Vachellia caven (Molina) Seigler \& Ebinger, ambas espinhosas e caducifólias, além da Aspidosperma quebracho-blanco Schltdl. (quebracho-branco).

Marchiori et al. (1983) estudando o gênero Prosopis no Rio Grande do Sul descrevem duas espécies do gênero nativas do estado, Prosopis algarobilla Gris. (atualmente identificada como Prosopis affinis Spreng.) e Prosopis nigra (Griseb.) Hieron. No entanto, para Prosopis nigra é a primeira citação para a flora nativa do Rio Grande do Sul, estando a mesma restrita às proximidades da barra do rio Quaraí.

De acordo com Marchiori et al. (1985) e Marchiori e Longhi (1985), outras espécies surgem junto aos Prosopis, principalmente a Vachellia caven, Aspidosperma quebracho-blanco e Parkinsonia aculeata L. (cina-cina). Formando pequenos 
agrupamentos aparecem Scutia buxifolia (coronilha), Guettarda uruguensis (veludinho), Sebastiania brasilienis (branquilho-leiteiro), Xylosma venosum (espinho-judeu), Chrysophylum marginatum (aguaí), Sapium glandulosum (L.) Morong. (toropi) e algumas mirtáceas. Além das espécies referenciadas anteriormente, outras espécies lenhosas ocorrem de forma esporádica, como: Acanthosyris spinescens (Mart. \& Eichler) Griseb. (sombra-de-touro), ParkinsoniaaculeataL. (cina-cina). Comum também é a ocorrência das epífitas e lianas Tillandsia duratti, Tillandsia ixioides e Exolous patens e das cactáceas Opuntia bonaerensis e Cereus uruguayanus. Reitz et al. (1983) ressaltam que, no Parque do Espinilho, o aspecto fitofisionômico é formado principalmente pelo gregarismo das duas espécies do gênero Prosopis, as quais se concentram principalmente nos arredores da Barra do Quaraí, constituindo-se de 90 a 98\% da vegetação arbórea do parque. Pode-se encontrar também com relativa frequência o espinilho, sendo que as três espécies são as que determinam o aspecto curioso, dando à vegetação um caráter xeromórfico.

Marchiori e Longhi (1985) salientam que esta vegetação constitui um prolongamento das formações do Parque Mesopotâmico localizado nas Províncias argentinas de Corrientes e Entre Rios. Tortorelli (1956 apud MARCHIORI e LONGHI, 1985) cita que o Parque Mesopotâmico é uma formação de caráter edáfico, ocorrendo na região sempre que o terreno se eleva em alguns metros, o que determina o desenvolvimento da vegetação sem ainfluência da água dos rios e arroios. Por este motivo, a vegetação é hidrófila na estreita faixa marginal aos cursos de água e passa a ter, nas partes altas, uma vegetação mesoxerofítica estando constituída por indivíduos dotados de particularidades fisiológicas que permitem maior resistência às condições menos favoráveis do meio, como: características químicas e físicas do solo, disponibilidade de água e nutrientes.

Recentemente outros locais do Rio Grande do Sul foram citados com ocorrência de inhanduvá (Prosopis affinis), como a região do Jarau em Quaraí (ALVES e MARCHIORI, 2010), parque do Loreto em São Vicente do Sul (MARCHIORI, DURLO, ALVES, 2011), várzea do rio Santa Maria em Rosário do Sul (ALVES e MARCHIORI, 2011a), várzea do rio Ibicuí e Cacequi (MARCHIORI e ALVES, 2011), planície de inundação do arroio Itapororó em Alegrete (ALVES e MARCHIORI, 2011b), indicando que a área de ocorrência natural desse tipo de vegetação foi bem maior antes da ação antrópica.

Estudos sobre a organização estrutural das populações deespéciesarbóreo-arbustivaséessencial para o conhecimento da ecologia das espécies. Baseia-se em levantamentos fitossociológicos, descrição florística, bem como do conhecimento do padrão de distribuição das espécies que compõem a vegetação, sendo estas base para a definição de estratégias de conservação de remanescentes e da restauração florestal de áreas degradadas.

O padrão de distribuição espacial é definido por Ludwig (1979) como a descrição quantitativa da distribuição horizontal de indivíduos de uma espécie dentro de uma comunidade vegetal. Em uma população, os indivíduos podem apresentar três padrões de distribuição espacial: aleatório, agrupado e uniforme.

A distribuição espacial das espécies num ambiente reflete o nível de adaptabilidade frente às diversas pressões seletivas, uma vez que devem existir condições essenciais à sobrevivência para que ocorra a ocupação e a colonização de determinado local. Desta forma, o estudo da composição florística e da distribuição espacial de populações biológicas fornece informações importantes para a compreensão dos fatores bióticos e abióticos determinantes da estruturação populacional e das interações ecológicas existentes.

$\mathrm{Na}$ vegetação objeto de estudo foram realizados trabalhos clássicos desenvolvidos em relação à descrição da vegetação, composição florística e estrutura fitossociológica (RAMBO, 1956; GARCIA et al., 1978; VELOSO e GÓESFILHO, 1982; REITZ et al., 1983; MARCHIORI et al., 1985; MARCHIORI e LONGHI, 1985; GALVANI, 2003) os quais apontam a existência de discordâncias em relação à ocorrência ou não de determinada espécie, bem como ao tipo de vegetação existente, e ressaltam a importância de realização de novos estudos.

Com base nas afirmações anteriores e ao caráter ímpar da vegetação do Parque Espinilho, de fundamental importância na manutenção da comunidade que preserva espécies endêmicas (Aspidosperma quebracho-blanco Schltdl.) e vulneráveis, constituindo-se também, conforme afirma Galvani (2003), um habitat significativo e importante para espécies de aves migratórias, justifica-se a realização do presente estudo.

Diante deste contexto, este trabalho teve por objetivo avaliar a composição florística, estrutura horizontal e vertical, bem como os padrões 
de distribuição espacial e agrupamento de espécies do componente arbóreo em uma amostra de Estepe Estacional Savanícola, localizada no Parque do Espinilho, Barra do Quaraí - RS.

\section{MATERIAL E MÉTODO}

A área da realização do presente estudo está localizada no município de Barra o Quaraí, no extremo sudoeste do estado do Rio Grande do Sul (Figura 1), a qual possui uma altitude média de 52 m. O Parque Estadual do Espinilho está inserido na Microbacia do Arroio Quaraí-chico, possuindo uma área de 1.617,14 há, conforme Decreto Estadual 41.444 de 28 de fevereiro de 2002.

O clima da região, conforme classificação de Köppen é Cfa, com médias anuais de temperatura de $23,4^{\circ} \mathrm{C}$, tendo a temperatura do mês mais quente inferior a $22{ }^{\circ} \mathrm{C}$ e a do mês mais frio superior a $3^{\circ}$ $\mathrm{C}$, com formação de geadas frequentes (MORENO, 1961). Pastore et al. (1986) acrescentam que o clima caracteriza-se por apresentar dupla estacionalidade, provocada por um período frio no inverno, alternado por um período subúmido e quente no verão. As chuvas são bem distribuídas durante todo o ano com uma média anual variando entre 1300 e $1500 \mathrm{~mm}$, apresentando índices médios mensais superiores a $100 \mathrm{~mm}$, o que não exclui a ocorrência de deficit hídrico nos meses mais quentes.

O solo do Parque do Espinilho está classificado como Chernossolos, moderadamente drenado, de coloração bruno-escura a brunoacinzentada muito escura, sendo derivados de diferentes litologias e sob vegetação de Savana e Estepe. Na sua grande maioria são utilizados com pastagens naturais e cultivos agrícolas. De uma maneira geral, os solos desta classe são de ótima fertilidade natural, no entanto, apresentam propriedades físicas adversas ao uso, principalmente com cultivos agrícolas (EMBRAPA, 2006).

A vegetação natural, classificada por Leite (1994) como Estepe Estacional Savanícola está associada ao xerofitismo. Para Reitz et al. (1983), o aspecto fisionômico da vegetação do Parque é determinado principalmente pelo gregarismo das duas espécies de Prosopis e Acacia caven, atualmente identificada por Vachellia caven (Molina) Seigler \& Ebinger que dão a vegetação o caráter xeromórfico, além da presença de floresta de galeria e pequenos agrupamentos de outras espécies.

Para o levantamento florístico e análise fitossociológica foi instalada uma unidade perma- nente de 4 ha $(200 \times 200 \mathrm{~m})$, subdividida em 400 subunidades de $100 \mathrm{~m}^{2}(10 \times 10 \mathrm{~m})$, onde todos os indivíduos arbóreos com circunferência $(\mathrm{C}) \geq 15,7$ $\mathrm{cm}$ a $30 \mathrm{~cm}$ do nível do solo foram amostrados e medidos com fita métrica. Também foram realizadas as medições da altura total de todas as árvores amostradas, utilizando-se o Hipsômetro Vertex III.

A identificação botânica foi realizada inicialmente in loco, bem como consultas ao Herbário do Departamento de Ciências Florestais (HDCF) da Universidade Federal de Santa Maria, RS. A elaboração da lista da composição florística foi organizada de acordo com o Sistema do APG, Angiosperm Phylogeny Group III (APG-III, 2009).

A estrutura horizontal foi avaliada pelos cálculos das estimativas dos parâmetros fitossociológicos tradicionalmente utilizados: densidade absoluta e relativa; dominância absoluta e relativa; frequência absoluta e relativa; valor de cobertura e valor de importância (MUELLERDUMBOIS e ELLENBERG, 1974). Já a estrutura vertical foi estudada pelo método do diagrama $h-\mathrm{M}$ apresentado por Sanquetta (1995), o qual permite representar graficamente a altura (h) de cada árvore na ordenada, em metros, e o valor médio cumulativo da variável h $(\mathrm{M})$, também em metros, no eixo das abscissas. A diversidade da floresta foi obtida pelo índice de diversidade de ShannonWeaner, que contempla duas variáveis (número de espécies e número de indivíduos de cada espécie); e a equabilidade de Pielou (J'), conforme Pielou (1969) e Magurran (1988), como forma de indicar o grau de uniformidade de indivíduos distribuídos entre as espécies.

Já a análise do padrão de distribuição espacial foi realizada utilizando-se o índice de Payandeh (1970), obtido por meio da relação entre a variância do número de árvores por parcela, e a média do número de árvores. Para fins de cálculo levou-se em consideração que as espécies deveriam ter no mínimo cinco indivíduos amostrados na área de estudo.

As estimativas dos parâmetros fitossociológicos, índice de diversidade e padrão de distribuição espacial, foram feitas com o software Mata Nativa 2.10 (CIENTEC, 2006). Os demais cálculos foram realizados com o uso da planilha eletrônica Excel (Microsoft ${ }^{\circledR}$ Oficce, 2003).

A determinação dos grupos florísticos, dentro da comunidade estudada, foi realizada pelo programa TWINSPAN, o qual verificou a ocorrência de padrões na distribuição das espécies, associados 


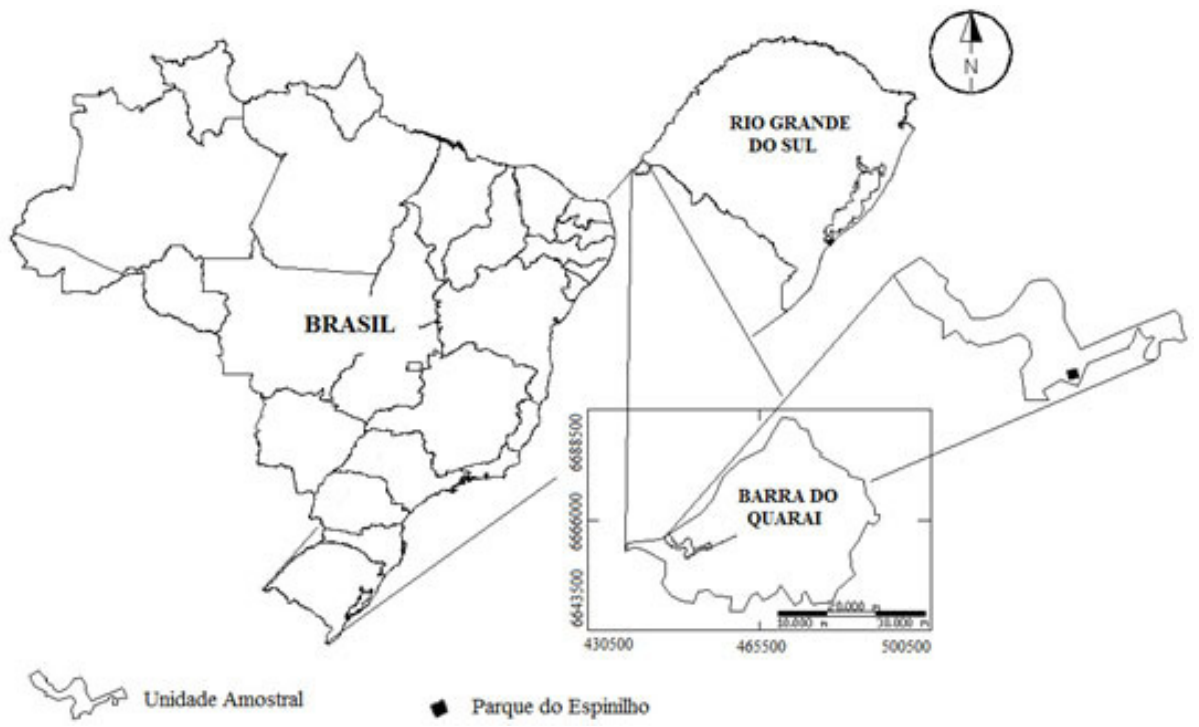

FIGURA 1: Área de estudo e localização da unidade amostral.

FIGURE 1: Study area and location of the sample plot.

às características locais (HILL, 1979; McCUNE e MEFFORD, 2006).

$\mathrm{Na}$ análise multivariada utilizou-se uma matriz de 234 × 7 , considerando as 234 unidades amostrais (linhas) e 7 espécies (colunas), ressalta-se que cada unidade amostral possui $100 \mathrm{~m}^{2}$. Os dados considerados foram de abundância das espécies porparcela, desprezando-se aquelas com menos de cinco indivíduos, as quais foram denominadas "raras" (apenas quatro espécies). Esse procedimento foi baseado na sugestão de Gauch (1982), que descreveu que as espécies com número reduzido de indivíduos apresentam pouca ou nenhuma influência sobre os resultados dos agrupamentos. Em cada divisão são apresentados os autovalores, que indicarão a significância dos grupos formados. Os autovalores maiores de 0,3 são adequados para explicar a variação encontrada na natureza (GAUCH, 1982; FELFILI e SEVILHA, 2001).

A visualização das espécies em eixos de ordenação foi realizada pela Análise de Componentes Principais. O gráfico de ordenação permite observar agrupamentos de espécies.

\section{RESULTADOS E DISCUSSÃO}

$\mathrm{Na}$ unidade de amostra de 4 ha foram amostrados 583 indivíduos distribuídos em 11 espécies, 10 gêneros e 8 famílias (Tabela 1). Somente o gênero Prosopis foi representado

TABELA 1: Relação das espécies amostradas na Estepe Estacional Savanícola, Barra do Quaraí (RS), 2009. TABLE 1: List of sampled species in Seasonal Steppe Savanna, in Barra do Quaraí (RS state) - Brazil, 2009.

\begin{tabular}{lll}
\hline Nome Popular & Nome Científico & Família \\
\hline Açoita-cavalo & Luehea divaricata Mart. \& Zucc. & Malvaceae \\
Aguaí-leiteiro & Chrysophyllum marginatum (Hook. \& Arn.) Radlk. & Sapotaceae \\
Algarroba & Prosopis nigra (Griseb.) Hieron. & Fabaceae \\
Branquilho & Sebastiania commersoniana (Baill.) L.B.Sm. \& Downs & Euphorbiaceae \\
Cambuí & Myrcia selloi (Spreng.) N. Silveira & Myrtaceae \\
Coronilha & Scutia buxifolia Reissek & Rhamnaceae \\
Espinilho & Vachellia caven (Molina) Seigler \& Ebinger & Fabaceae \\
Inhanduvá & Prosopis affinis Spreng. & Fabaceae \\
Quebracho-branco & Aspidosperma quebracho-blanco Schltdl. & Apocynaceae \\
Toropi & Sapium haematospermum Müll. Arg. & Euphorbiaceae \\
Veludinho & Guettarda uruguensis Cham. \& Schltdl. & Rubiaceae \\
\hline
\end{tabular}


por duas espécies, Prosopis nigra (algarroba) e Prosopis affinis (in-handuvá), os demais gêneros foram representados por somente uma espécie. Comparando esses resultados com os de outros obtidos na região (SIMAS et al., 2002; GALVANI, 2003), observou-se que a unidade amostral grande utilizada no presente trabalho possibilitou a amostragem de outras espécies comuns na área do parque, ocorrentes em pequenos grupos.

Resultados semelhantes foram encontrados por Marchiori e Longhi (1985) em área próxima ao do presente estudo, onde amostraram 10 espécies de 9 gêneros, sendo o gênero Prosopis representado pelas mesmas duas espécies. Os autores ressaltaram ainda que a vegetação foi caracterizada pela ocorrência expressiva das duas espécies de Prosopis, além de Aspidosperma quebracho-blanco e Parkinsonia aculeata L. (cina-cina).

A família melhor representada na área foi Fabaceae, a qual além de possuir o maior número de espécies foi a que possui o maior número de indivíduos, $62,1 \%$ do total. Já a família Euphorbiaceae apesar de possuir duas espécies, contribuiu com apenas $0,5 \%$ do total de indivíduos.

A área do presente estudo apresentou diversidade florística com índice de Shannon calculado em 1,86, indicando baixa diversidade. No estudo de Giménez et al. (2007), o índice variou entre 2,02 em Buen Lugar e 2,60 no Parque Los Quebrachos, revelando que as espécies estão bem representadas. Já Ramos (2008) encontrou 1,88 , afirmando que foi encontrada uma menor diversidade do que era es-perado. No trabalho de Ramos (2008) foi amostrada uma área de $2600 \mathrm{~m}^{2}$ e Gimenez et al. (2007) a área amostral foi de 500 $\mathrm{m}^{2}$ para cada uma das áreas, ressalta-se que estes valores diferenciados de área podem influenciar na determinação do índice de diversidade.

O índice de equabilidade de Pielou estimado foi de 0,75 , representando uma uniformidade média. $\mathrm{O}$ valor encontrado determina certa dominância ecológica de poucas espécies predominando na comunidade. Já o coeficiente de mistura de Jestsch $(1: 48,58)$, indicou que existem, em média, na vegetação arbórea, 48,58 indivíduos por espécie.

Os resultados fitossociológicos indicaram que foram amostrados 571 indivíduos arbóreos vivos e 12 mortos em pé, perfazendo um total de 583 indivíduos, o que significou uma densidade estimada de 145 indivíduos por hectare.

TABELA 2: Estimativa dos parâmetros fitossociológicos das espécies amostradas na Estepe Estacional Savanícola, Barra do Quaraí (RS), 2009.

TABLE 2: Estimated Phytosociologycal parameters for the sampled species in the Seasonal Steppe Savanna, in Barra do Quaraí (RS state) - Brazil, 2009.

\begin{tabular}{lccccccccc}
\hline \multirow{2}{*}{ Espécie } & $\mathrm{N}$. & $\mathrm{DA}$ & $\mathrm{DoA}$ & $\mathrm{FA}$ & $\mathrm{DR}$ & $\mathrm{DoR}$ & $\mathrm{F} \mathrm{R}$ & $\mathrm{V} \mathrm{C}$ & $\mathrm{V} \mathrm{I}$ \\
\cline { 2 - 9 } & $\mathrm{Ind}$. & $\mathrm{Ind} / \mathrm{ha}$ & $\mathrm{m}^{2} / \mathrm{ha}$ & $\%$ & $\%$ & $\%$ & $\%$ & $\%$ & $\%$ \\
\hline $\begin{array}{l}\text { Prosopis nigra } \\
\text { Aspidosperma quebracho- }\end{array}$ & 143 & 35,75 & 1,15 & 20,75 & 24,53 & 28,46 & 24,63 & 26,49 & 25,86 \\
-blanco & & & & & & & & & \\
Prosopis affinis & 113 & 28,25 & 1,17 & 21,50 & 19,38 & 28,84 & 25,52 & 24,11 & 24,57 \\
Vachellia caven & 149 & 37,25 & 0,86 & 22,00 & 25,56 & 21,24 & 26,11 & 23,4 & 24,30 \\
Scutia buxifolia & 70 & 17,50 & 0,30 & 10,25 & 12,01 & 7,35 & 12,17 & 9,68 & 10,51 \\
Myrcia selloi & 45 & 11,25 & 0,28 & 1,75 & 7,72 & 6,87 & 2,08 & 7,29 & 5,55 \\
Chrysophyllum marginatum & 18 & 4,50 & 0,08 & 2,00 & 3,09 & 1,88 & 2,37 & 2,48 & 2,45 \\
Mortas & 12 & 3,00 & 0,05 & 3,00 & 2,06 & 1,31 & 3,56 & 1,68 & 2,33 \\
Sapium haematospermum & 2 & 0,50 & 0,02 & 0,50 & 0,34 & 0,55 & 0,59 & 0,44 & 0,49 \\
Luehea divaricata & 3 & 0,75 & 0,01 & 0,25 & 0,51 & 0,23 & 0,30 & 0,37 & 0,35 \\
Sebastiania commersoniana & 1 & 0,25 & 0,01 & 0,25 & 0,17 & 0,15 & 0,30 & 0,16 & 0,20 \\
Guettarda uruguensis & 1 & 0,25 & 0,00 & 0,25 & 0,17 & 0,07 & 0,30 & 0,12 & 0,18 \\
\hline Total & 583 & 145,75 & 4,06 & 84,25 & 100 & 100 & 100 & 100 & 100 \\
Enylyyyyyyyyyy
\end{tabular}

Em que: $\mathrm{N}=$ número total de indivíduos amostrados; $\mathrm{DA}=$ densidade absoluta (ind ha ${ }^{-1}$ ); DoA = dominância absoluta $\left(\mathrm{m}^{2} \mathrm{ha}^{-1} ; \mathrm{FA}=\right.$ frequência absoluta $(\%) ; \mathrm{DR}=$ densidade relativa $(\%)$; DoR = dominância relativa $(\%) ; \mathrm{FR}=$ frequência relativa (\%); $\mathrm{VC} \%=$ valor de cobertura; $\mathrm{VI} \%$ = valor de importância. 
0,Na Tabela 2 são apresentados os resultados das estimativas dos parâmetros fitossociológicos, cujas espécies foram listadas em ordem decrescente, de acordo com o Valor de Importância (VI\%).

Os valores de densidade diferem de outros estudos analisados. Marchiori e Longhi (1985) encontraram 97 árvores/ha, valores inferiores aosencontrados no presente estudo. Marchiori et al. (1985), Araujo et al. (2008) e Ramos (2008) encontraram valores maiores, respectivamente 339 , 246 e 822 árvores/ha.

A grande densidade de árvores/ha encontrada por Ramos (2008) é justificada em função da classe mínima amostral inferior ao dos outros levantamentos, bem como afirmou o próprio autor, tanto a Parkinsonia aculeata como a Vachellia caven serem espécies que possuem grande capacidade de rebrotar da raiz e também possuírem características de serem pioneiras com grande habilidade de colonização, sendo 322 árvores/ha de Parkinsonia aculeata e 89 árvores/ha de Vachellia caven.

As espécies com os maiores valores de importância foram Prosopis nigra (25,86\%), Aspidosperma quebracho-blanco $(24,57 \%)$, Prosopis affinis (24,30\%) e Vachellia caven (10,51\%), representando $85,26 \%$ do valor de importância total. Com relação à densidade, notou-se que estas espécies representaram $81,48 \%$ do total de indivíduos amostrados.

Marchiori et al. (1985) em estudo realizado na mesma área relataram as mesmas espécies que apresentaram valores de importância distintos ao estudo, com Prosopis nigra (36,35\%), Aspidosperma quebracho-blanco (20,41\%), Vachellia caven (19,73\%) e Prosopis affinis (7,80\%). Deve-se ressaltar que os autores referenciaram ainda a Parkinsonia aculeata $(5,57 \%)$ como sendo espécie característica desta vegetação, mas de importância fitossociológica menor.

Em trabalhos de outras áreas do Parque, os autores anteriormente referenciados encontraram valores de importância diferentes do presente estudo, para as espécies de Prosopis, invertendo a sequência de importância, Prosopis affinis (69,52\%), Prosopis nigra (20,28\%) e Vachellia caven $(10,20 \%)$. Resultados obtidos por Galvani (2003) também diferem do presente estudo, o qual indica ser Prosopis affinis (49,97\%) a espécie com maior valor de importância, seguida por Prosopis nigra $(22,21 \%)$ e Vachellia caven $(16,66 \%)$. No estudo realizado pelo autor, o Aspidosperma quebracho-blanco apareceu como a quinta espécie em valor de importância com apenas $1,53 \%$, valor este que diferiu também do presente estudo, onde a espécie foi a segunda colocada com $24,57 \%$ de valor de importância.

No levantamento realizado por Ramos (2008), as quatro espécies com maior valor de importância foram: Parkinsonia aculeata, Sebastiania commersoniana, Myrcia selloi e Vachellia caven, respectivamente com 29,28; 15,14; 9,97 e $9,82 \%$.

Em relação à distribuição das espécies na área estudada, expressa pela frequência absoluta, Prosopis affinis foi a mais bem distribuída (22\%), seguida por Aspidosperma quebracho-blanco (21,50\%), Prosopis nigra (20,75\%) e Acacia caven (10,25\%). Para Ramos (2008), Vachellia caven teve $67 \%$ de ocorrência, e Parkinsonia aculeata ocorreu em $100 \%$ das unidades amostrais, mostrando que a espécie estava distribuída em toda a área do estudo realizado.

No levantamento realizado por Galvani (2003), também o Prosopis affinis foi à espécie amostrada com melhor distribuição, ocorrendo em $35,7 \%$ das unidades amostrais, seguida por Vachellia caven $(28,9 \%)$ e Prosopis nigra (26,1\%). O autor também observou que somente em uma parcela ocorreu a presença de Aspidosperma quebrachoblanco, estando a espécie restrita à região do Parque do Espinilho, e com raros indivíduos.

Resultados diferentes foram relatados por Araujo et al. (2008), os quais encontraram no seu estudo na região do Chaco Semiárido Argentino o Aspidosperma quebracho-blanco como a espécie mais frequente $(40,91 \%)$ e com uma distribuição mais regular, sendo que o Prosopis nigra apareceu como a segunda espécie mais frequente ocorrendo em $26,42 \%$ das unidades amostrais.

A área basal estimada para a formação estudada foi de $4,06 \mathrm{~m}^{2} / \mathrm{ha}$, inferior à encontrada por Araujo et al. (2008) na cidade de Santiago del Estero, Argentina, onde reportaram terem encontrado 6,76 $\mathrm{m}^{2} /$ ha, sendo que $44,97 \%$ desta área basal são de Aspidosperma quebracho-blanco $\left(3,04 \mathrm{~m}^{2} / \mathrm{ha}\right)$ e Prosopis nigra $\left(0,32 \mathrm{~m}^{2} / \mathrm{ha}\right)$. O valor encontrado foi superior ao encontrado por Ramos (2008) de 2,56 $\mathrm{m}^{2} /$ ha, sendo que deste valor $0,95 \mathrm{~m}^{2} /$ ha pertencia à Parkinsonia aculeata e $0,28 \mathrm{~m}^{2} /$ ha à Vachellia caven.

Pode-se verificar que os resultados estimados foram inferiores aos relatados por Sachtler (1977), onde as florestas com área basal 
pela sua área basal indicou como mais dominantes o Aspidosperma quebracho-blanco com $1,15 \mathrm{~m}^{2} /$ ha $(28,84 \%)$, Prosopis nigra com $1,15 \mathrm{~m}^{2} / \mathrm{ha}$ $(28,46 \%)$, Prosopis affinis com $0,86 \mathrm{~m}^{2} / \mathrm{ha}(21,24 \%)$ e Vachellia caven com $0,30 \mathrm{~m}^{2} / \mathrm{ha}(7,35 \%)$.

$\mathrm{Na}$ área de estudo foram encontrados alguns pequenos agrupamentos compostos com espécies arbóreas, destacando-se a coronilha (Scutia buxifolia), a qual possui densidade de 11,25 indivíduos por hectare com uma dominância de $0,28 \mathrm{~m}^{2} /$ ha, sendo esta espécie a quinta em valor de importância.

Os indivíduos amostrados foram distribuídos em oito classes de circunferência (Figura 2). Na primeira classe $(12,5 \mathrm{~cm})$ ocorreram $42 \%$ das árvores amostradas, sendo que $78 \%$ destas árvores pertenciam à Prosopis affinis (26,1\%), Vachellia caven (18,7\%), Prosopis nigra (17\%) e Aspidosperma quebracho-blanco $(16,2)$, conforme observado na Figura 4.

A maior árvore registrada na amostragem foi de Aspidosperma quebracho-blanco com 47,2 $\mathrm{cm}$ de circunferência e altura total de $8,20 \mathrm{~m}$. Podese ressaltar que árvores com grandes dimensões, somente foram registradas de Aspidosperma quebracho-blanco, como observado na Figura 3(d). Para as árvores de menores diâmetros, além das espécies características da vegetação em estudo, foram observados Myrcia selloi (cambuí), Pouteria salicifolia (aguaí-leiteiro), Scutia buxifolia (coronilha), Luehea divaricata (açoita-cavalo) e Guettarda uruguensis (veludinho).

A estrutura diamétrica revelou a comuni- dade arbórea composta principalmente por árvores pequenas, cujo número de indivíduos diminui para as classes de maior diâmetro, seguindo o modelo "J Invertido" ou exponencial-negativo, característico de florestas com populações inequiâneas. Para Silva Junior (2004), o padrão da curva, indica balanço positivo entre o recrutamento e mortalidade e caracteriza uma vegetação como autorregenerante.

Entretanto, quando se analisou a espécie Prosopis affinis (Figura 3a), Vachellia caven (Figura 3b), Prosopis nigra (Figura 3c) e Aspidosperma quebracho-blanco (Figura 3d) isoladamente, observou-se que somente a Prosopis nigra não seguiu o mesmo padrão da comunidade. Tal variação pode estar relacionada à questão da espécie apresentar síndrome de dispersão zoocórica, aspecto que pode estar relacionado ao empobrecimento da fauna dispersora, principalmente a ema (Rhea americana), não mais avistada dentro dos limites do Parque. Outros aspectos que afetaram as variações podem estar relacionados à ecologia populacional da espécie, bem como aos históricos de perturbações da área estudada.

Marchiori e Longhi (1985) já mencionaram outro aspecto que pode estar relacionado à distribuição do Prosopis nigra, segundo o qual a regeneração natural do Prosopis nigra e Prosopis affinis é baixa, não assegurando a reposição destas espécies na vegetação, apesar de boa germinação das sementes, devido, principalmente pela ação do pastoreio. Além do pastoreio, outro aspecto ressaltado foi o uso do fogo, ou mesmo pela utilização da madeira das espécies de Prosopis

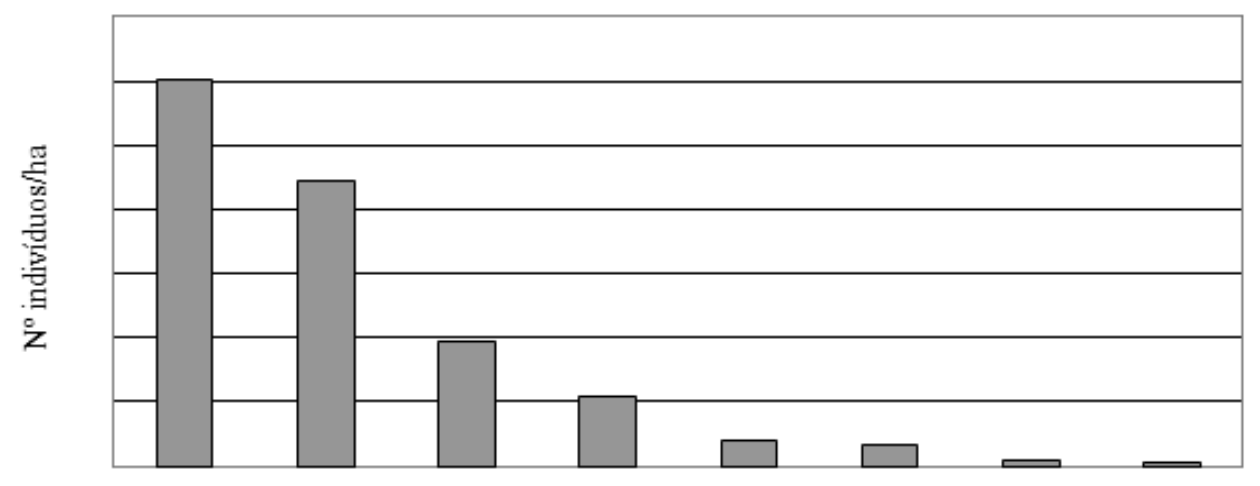

Centro de classe de circunferência $(\mathrm{cm})$

FIGURA 2: Distribuição diamétrica das espécies amostradas na Estepe Estacional Savanícola, Barra do Quaraí (RS), 2009.

FIGURE 2: Diameter distribution of sampled species in the Seasonal Steppe Savanna, Barra do Quaraí (RS state) - Brazil, 2009. 


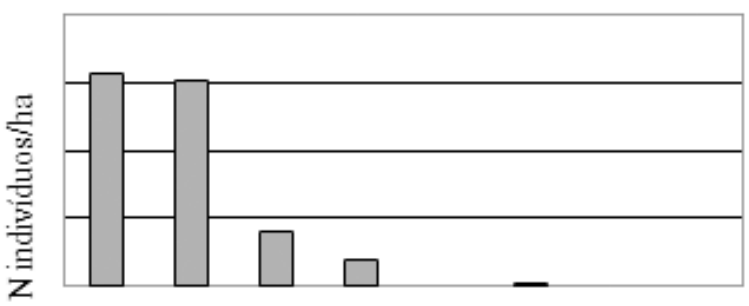

Centro de classe de circunferência $(\mathrm{cm})$

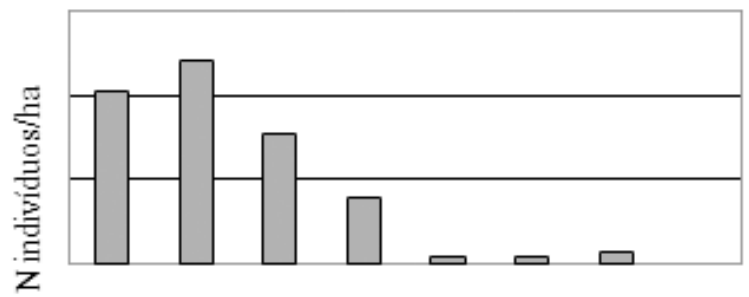

Centro de classe de circunferência $(\mathrm{cm})$

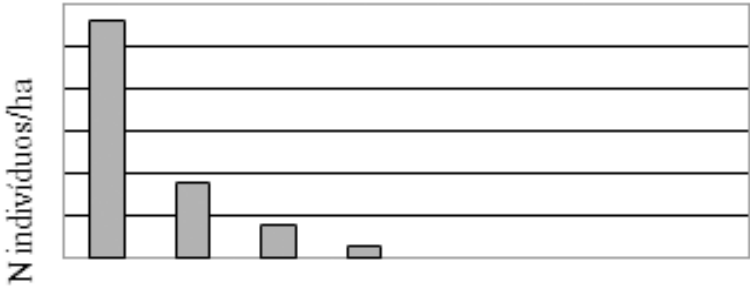

Centro de classe de circunferência $(\mathrm{cm})$

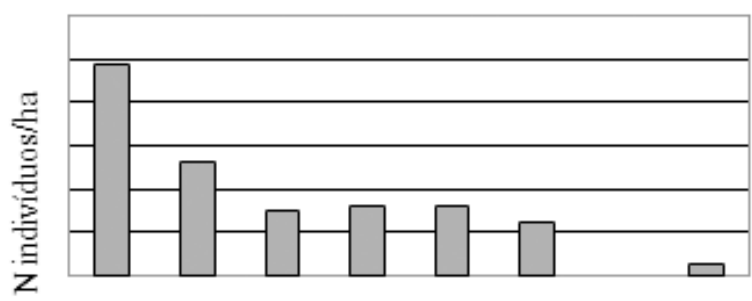

Centro de classe em circunferência $(\mathrm{cm})$

FIGURA 3: Distribuição diamétrica das quatro espécies amostradas com maiores valores de importância na Estepe Estacional Savanícola, Barra do Quaraí (RS), 2009.

FIGURE 3: Diameter distribution of sampled species with the highest importance values in a Seasonal Steppe Savannah, Barra do Quaraí (RS) - Brazil, 2009.

decorrente da alta durabilidade.

$\mathrm{Na}$ Figura 4 encontra-se apresentado o diagrama h-M para a Savana Estépica Parque, identificando dois estratos, os quais podem ser reconhecidos pela mudança no curso retilíneo no diagrama, indicado pela seta. $\mathrm{O}$ estrato superior (Estrato II) com alturas superiores a 7,4 m, e o estrato inferior (Estrato I) com alturas inferiores a este valor.

$\mathrm{O}$ estrato superior representou apenas $6,7 \%$ do total de árvores amostradas. Compõem este estrato as seguintes espécies: Aspidosperma quebracho-blanco $\quad(70,0 \%), \quad$ Myrcia selloi (25\%), Scutia buxifolia (7,5\%) e Chrysophyllum marginatum $(2,5 \%)$. Com exceção da primeira espécie, considerada característica da vegetação em estudo encontrada de forma isolada, as demais estavam agrupadas em capões de floresta entremeados com a vegetação campestre natural. Também é importante ressaltar a inexistência de árvores mortas neste estrato, aspecto este que chama a atenção, principalmente por tratar-se de árvores mais velhas, mesmo que representado, em quase sua totalidade, por uma única espécie.

TABELA 3: Padrão de distribuição espacial das espécies amostradas na Estepe Estacional Savanícola, Barra do Quaraí (RS), 2009.

TABLE 3: Spatial distribution of sampled species in the Seasonal Steppe Savannah, Barra do Quaraí (RS state) - Brazil, 2009.

\begin{tabular}{lcc}
\hline \multicolumn{1}{c}{ Nome Científico } & Índice de Payandeh & Classificação \\
\hline Prosopis nigra & 2,21 & Agrupada \\
Aspidosperma quebracho-blanco & 1,43 & Tendência ao agrupamento \\
Prosopis affinis & 2,11 & Agrupada \\
Vachelia caven & 3,00 & Agrupada \\
Scutia buxifolia & 11,81 & Agrupada \\
Myrcia selloi & 9,50 & Agrupada \\
Chrysophyllum marginatum & 3,19 & Agrupada \\
\hline
\end{tabular}




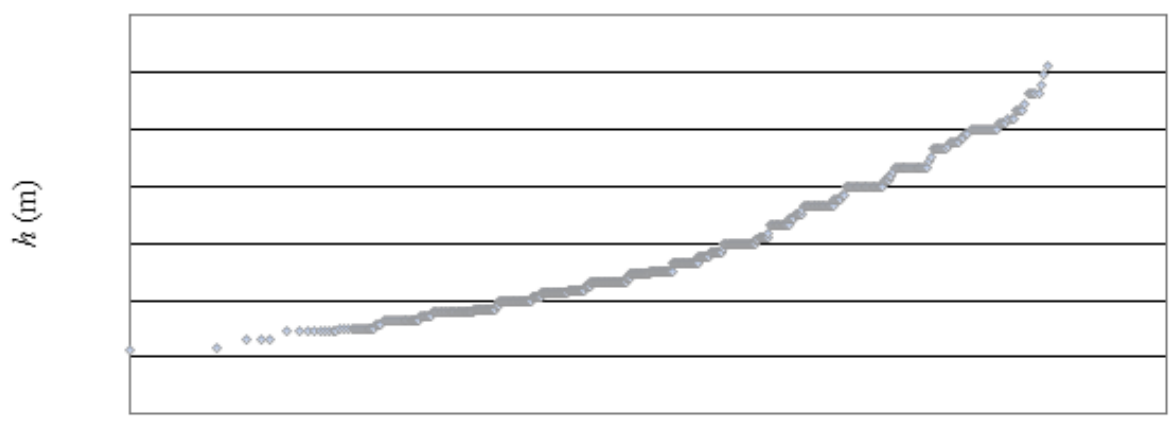

$\mathrm{M}(\mathrm{m})$

FIGURA 4: Estratificação utilizando o Diagrama h-M na Estepe Estacional Savanícola, Barra do Quaraí (RS), 2009.

FIGURE 4: Vertical stratification with the h-M diagram for the Seasonal Steppe Savannah, Barra do Quaraí (RS state) - Brazil, 2009.

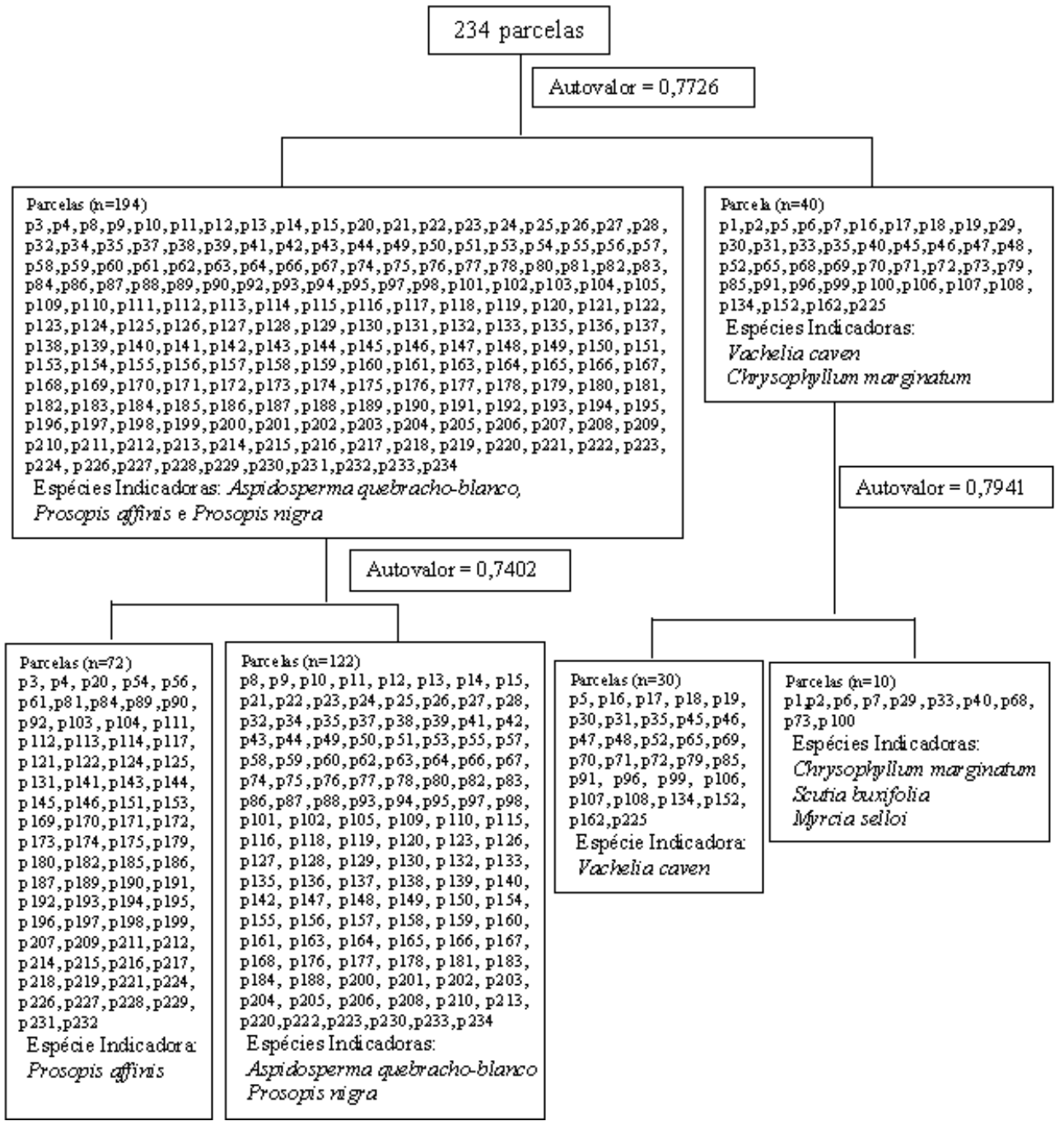

FIGURA 5: Análise de agrupamento das parcelas avaliadas na Estepe Estacional Savanícola, através do método Twinspan, para as espécies com mais de 5 indivíduos, Barra do Quaraí (RS), 2009.

FIGURE 5: Cluster analysis of sampled plots in the Seasonal Steppe Savannah using the Twin span metod for species with more than 5 individuals, Barra do Quaraí (RS state) - Brazil, 2009. 
No estrato inferior (Estrato I) ocorrem 93,3\% do total das árvores, como também a maior diversidade de espécies, com ocorrência de todas as espécies encontradas no presente levantamento. Conforme observado na Figura 4, o estrato possuía uma continuidade, as alturas variaram entre os valores de $1,7 \mathrm{~m}$ e 7,3 $\mathrm{m}$. As espécies características da vegetação representaram mais de $81,8 \%$ do total do estrato, sendo estas Prosopis affinis (27,3\%), Prosopis nigra (26,2\%), Aspidosperma quebrachoblanco (15,7\%) e Vachellia caven (12,7\%). Ao contrário do Estrato I, ocorreram árvores mortas, representando $0,6 \%$ do total.

Em trabalho no Parque Los Quebrachos Santos Lugares-Alberdo, Giménez et al. (2007) relataram a existência de dois estratos na vegetação arbórea, um inferior, com altura entre 6 a 8 metros, composto por espécies secundárias como Ziziphus mistrol, Prosopis ruscifolia, Cercidium praeuox, Prosopis nigra, Geoffroea decorticans, Tabebuia nodosa e Jodina rhombifolia. Já o estrato superior foi formado por Schinopsis lorentzii e Aspidosperma quebracho-blanco com uma altura entre 12 a 20 metros.

As estimativas dos padrões de distribuição espacial, das espécies arbóreas amostradas podem ser observadas na Tabela 3.

Pela análise, $85,7 \%$ das espécies utilizadas para fins de cálculo possuem padrão de distribuição agrupado, com exceção de Aspidosperma quebracho-blanco que, entre as principais espécies da comunidade, apresentou distribuição com tendência ao agrupamento. O predomínio do padrão agregado observado corrobora com a afirmação de Teixeira e Assis (2007), os quais destacam que este padrão foi o mais comumente observado na natureza. $A$ pesar de possuírem pequena frequência, as espécies Scutia buxifolia, Myrcia selloi e Chrysophyllum marginatum, possuíram padrão de distribuição agrupada, com ocorrências em pequenas manchas, possivelmente dispersadas por pássaros em puleiros.

$\mathrm{Na}$ comunidade estudada foram observados quatro grupos florísticos distintos (Figura 5).

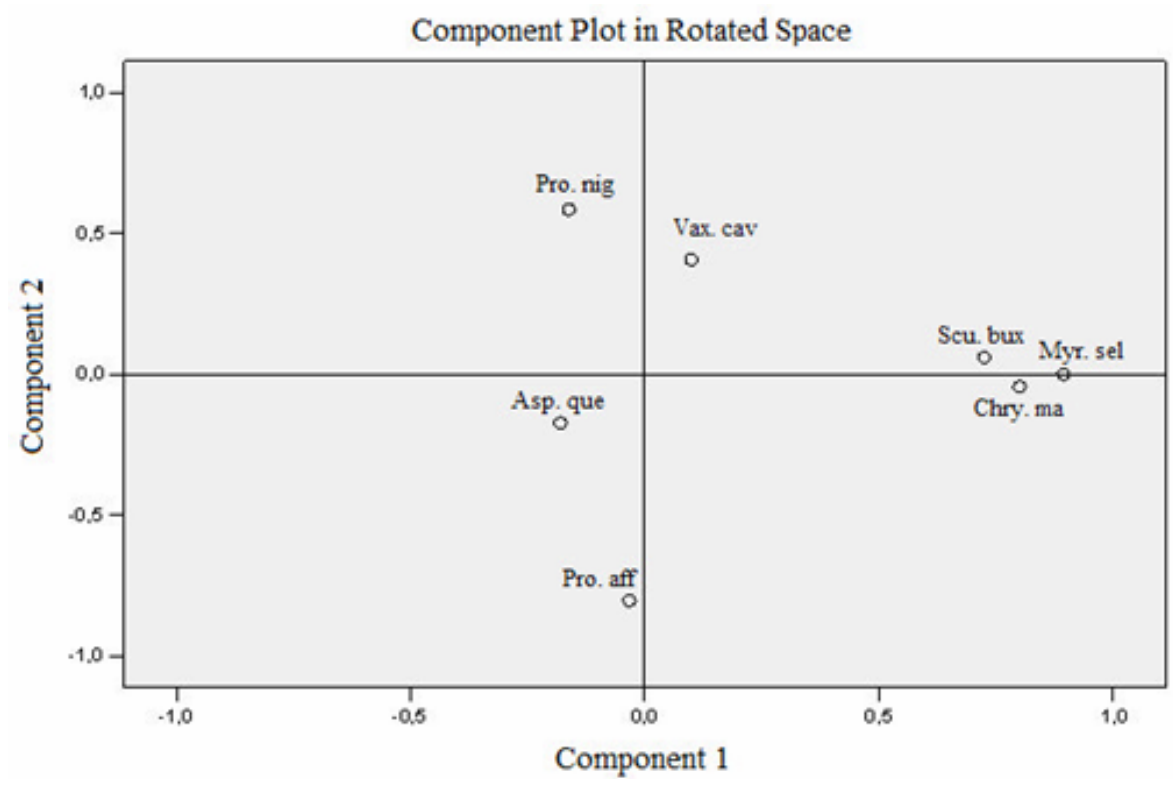

FIGURA 6: Distribuição das espécies em eixos coordenados através da análise de Componentes Principais na Estepe Estacional Savanícola, Barra do Quaraí (RS), 2009.

Legenda: Pro.nig = Prosopis nigra, Vac. cav = Vachelia caven, Scu. bux = Scutia buxifolia, Myr. sel = Myrcia selloi, Asp. que = Aspidosperma quebracho-blanco, Pro. aff $=$ Prosopis affinis, Chy. ma $=$ Chrysophyllum marginatum.

FIGURE 6: Species distribution on the coordinate axis according to the Principal Components Analysis in the Seasonal Steppe Savannah, Barra do Quaraí (RS state) - Brazil, 2009.

Legend: Pro.nig = Prosopis nigra, Vac. cav = Vachelia caven, Scu. bux $=$ Scutia buxifolia, Myr. sel = Myrcia selloi, Asp. que $=$ Aspidosperma quebracho-blanco, Pro. aff $=$ Prosopis affinis, Chy. ma = Chrysophyllum marginatum. 
A primeira divisão, com autovalor igual a 0,7726 (alta significância), dividiu as 234 parcelas em dois grupos. O grupo da esquerda juntou 194 parcelas, tendo Aspidosperma quebracho-blanco, Prosopis nigra e Prosopis affinis como espécies indicadoras. Já o grupo da direita juntou 40 parcelas, tendo Vachellia caven e Chrysophyllum marginatum como espécies indicadoras. Tal divisão pode ser visualizada no diagrama de ordenação obtido pelo método dos com-ponentes principais (Figura 6).

A segunda divisão, com autovalor de 0,7402 (alta significância), dividiu as 194 parcelas da esquerda em dois grupos. O Grupo 1 (com 72 parcelas), que apresentou Prosopis affinis como espécie indicadora, ocorreu em parcelas localizadas em área mais seca afastada do contato com Aspidosperma quebracho-blanco. Constitui a formação típica de Parque, que caracteriza a maior área do Parque Espinilho não analisada neste trabalho, localizada no outro lado da rodovia BR. O Grupo 2 (com 122 parcelas) apresentou Aspidosperma quebracho-blanco e Prosopis nigra, como espécies indicadoras (Figura 6). São espécies, que ocorrem associadas, em áreas que em certos períodos do ano (inverno) apresentam-se com maior umidade.

A terceira divisão, com autovalor de 0,7941 (alta significância), dividiu as 40 parcelas da direita na primeira divisão também em dois grupos. $\mathrm{O}$ grupo da esquerda, denominado de Grupo 3 (com 30 parcelas) apresentou Vachellia caven como espécie indicadora. É o grupo dos espinilhos típicos, comuns nas formações de Estepes Parques da fronteira oeste do Rio Grande do Sul. O grupo da direita, denominado Grupo 4 (com 10 parcelas) tendo Chrysophyllum marginatum, Scutia buxifolia e Myrcia selloi como espécies indicadoras (Figuras 5 e 6). São pequenas formações (capões) de forma arredondada com cerca de $5 \mathrm{~m}$ de diâmetro, formadas por sementes levadas pelos pássaros em puleiros.

A evidência da presença desses quatro grupos na área estudada é perfeitamente visualizada e comum nessas formações de Parque na região da Barra do Quaraí, (RS) e caracteriza bem essa importante comunidade vegetal, única no Brasil.

\section{CONCLUSÕES}

A Estepe Estacional Savanícola estudada é caracterizada principalmente pela ocorrência de Aspidosperma quebracho-blanco, Prosopis nigra,
Prosopis affinis e Vachellia caven, constituindo-se em uma associação de espécies única no Brasil, apresentando questão de raridade em termos de composição de espécies e estrutura.

$\mathrm{Na}$ área estudada foram definidas quatro comunidades distintas: Associação Prosopis nigra com Aspidosperma quebracho-blanco em áreas mais úmidas, Formação de Prosopis affinis, Formação de Vachellia caven em áreas mais secas e pequenos agrupamentos de espécies típicas da floresta ciliar dos rios da região entremeados à vegetação de espinhal.

A análise fitossociológica da área de estudo no Parque do Espinilho comprovou se tratar de área com ocorrência endêmica de Prosopis no Brasil, sendo fundamental sua manutenção como parque integrante do Sistema Nacional de Unidade de Conservação. Nesse sentido e pela singularidade da área é necessária a efetiva instalação do Parque do Espinilho com a imediata retirada de animais domésticos da área.

\section{REFERÊNCIAS BIBLIOGRÁFICAS}

ALVES, F. da S.; MARCHIORI, J. N. C. O Inhanduvá (Prosopis affinis Spreng.) no Rio Grande do Sul. 2-Ocorrência Natural na região do Jarau, Quaraí. Balduinia, Santa Maria, n. 25, p. 1-9, 2010. ALVES, F. da S.; MARCHIORI, J. N. C. O Inhanduvá (Prosopis affinis Spreng.) no Rio Grande do Sul. 5-Ocorrência Natural na várzea do rio Santa Maria, Rosário do Sul. Balduinia, Santa Maria, n. 27, p. 1-7, 2011a.

ALVES, F. da S.; MARCHIORI, J. N. C. O Inhanduvá (Prosopis affinis Spreng.) no Rio Grande do Sul. 7-Ocorrência Natural na planície de inundação do Arroio Itapororó, município de Alegrete. Balduinia, Santa Maria, n. 28, p. 1-7, 2011b.

APG - III. Angiosperm Phylogeny Group. An update of the angiosperm phylogeny group classification for the orders and families of flowering plants: APG III. Boutanical Journal of the Linean Society, v. 161, p.105-121, 2009.

ARAUJO, P. et al. Estructura del bosque de La María EEA INTA Santiago del Estero. Quebracho, Santiago del Estero, v. 16, p. 5-19, 2008.

CIENTEC - Consultoria e Desenvolvimento de Sistemas Ltda. Software Mata nativa 2: Sistema para análise fitossociológica e elaboração de inventários e planos de manejo de florestas nativas. Viçosa, Cientec, 2001-2006. 
EMBRAPA. Centro Nacional de Pesquisa de Solos. Sistema brasileiro de classificação de solos. 2. ed. Rio de Janeiro, 2006. 306 p.

FELFILI, J. M.; SERVILHA, A. C. Distribuição espacial de parcelas e de espécies em quatro áreas de cerrado sensu stricto na Chapada do Espigão Mestre de São Francisco. In: FELFILI, J. M.; SILVA Jr., M. C. da (org.). Biogeografia do bioma Cerrado: estudo fitofisiônomico na Chapada do Espigão Mestre do São Francisco. Brasília: UnB, 2001, p. 61- 74. GALVANI, F. R. Vegetação e aspectos ecológicos do Parque Estadual do Espinilho, Barra do Quaraí, RS. 2003. 154 f. Tese (Doutorado em Botânica) - Universidade Federal do Rio Grande do Sul, Porto Alegre, 2003.

GARCIA, I. S. et al. Vegetação atual da Região Sul. Porto Alegre: Ministério do Interior, Superintendência do Desenvolvimento da Região Sul, 1978. 108 p.

GAUCH, H. G. Multivariate analysis in community ecology. Cambridge: Cambridge University Press, 1982. 180 p.

GIMÉNEZ, A. M. et al. Diversidad vegetal en siete unidades demostrativas del chaco semiárido argentino. Madera y Bosques, Xalapa, v. 13, p. 6178, 2007.

GRULKE, M. Una propuesta de manejo silvipastoril para zonas del Chaco Saltenõ. Informe final de la práctica NADEL. Eidgneössishe - Technische Hochschule Zürich. 1994. 150 p.

HILL, M. O. TWINSPAN: a FORTRAN program fo arranging multivariate data in an ordered two way table by classification of individual and attributes. Ithaca, NY: Cornell University, 1979. 60 p.

IBGE. Manual técnico da vegetação brasileira. Rio de Janeiro: 1991. 92 p.

LEITE, P. F. As diferentes unidades fitogeográficas da Região Sul do Brasil. Curitiba: UFPR, 1994. 160 f. Dissertação (Mestrado em Engenharia Florestal) - Universidade Federal do Paraná, Curitiba, 1994.

LUDWIG, J. A. A test of different quadrat variance methods for the analysis of spatial pattern In: CORMACK, R. M., ORD, J. K. (Eds.). Spatial and temporal analysis in ecology. Fairland: International Co-operative Publ., 1979. p. 289-304. (Statistical ecology, 8).

McCUNE, B.; MEDDORF, M. J. PC-ORD: multivariate analysis of ecological data. Version 6.0. Oregon: MjM Software Desing, 2011. 28 p.

MAGURRAN, A. E. Diversidad Ecológica e su Medición. Barcelona: Vedra, 1988. 200 p.

MARCHIORI, J. N. C. et al. O Inhanduvá (Prosopis affinis Spreng.) no Rio Grande do Sul. 3-Parque da Cabanha do Loreto, São Vicente do Sul. Balduinia, Santa Maria, n. 25, p. 22-31, 2010.

MARCHIORI, J. N. C.; ALVES, F. da S. O Inhanduvá (Prosopis affinis Spreng) no Rio Grande do Sul. 6-Descrição de um parque natural na várzea do rio Ibucí, município de Cacequi. Balduinia, Santa MARIA, n. 27, p. 20-26, 2011. MARCHIORI, J. N. C. et al.. O gênero Prosopis L. (Leguminosae-Mimosoidaeae) no Rio Grande do Sul. Ciência e Natura, Santa Maria, v. 5, p. 171162, 1983.

MARCHIORI, J. N. C.; LONGHI, S. J. Estrutura fitossociológica de uma associação natural de Parque Inhanduvá com Quebracho e Cina-Cina, no Rio Grande do Sul. Ciência e Natura, Santa Maria, v. 7, p. 147-162, 1985.

MARCHIORI, J. N. C. et al.Composição florística e estrutura do Parque de Inhanduvá no Rio Grande do Sul. Revista do Centro de Ciências Rurais, Santa Maria, v. 15, n. 4, p. 319-334, 1985.

MICROSOFT OFICCE EXCEL. Parte do produto Microsoft Office Professional 2003.

MOREnO, J. A. Clima do Rio Grande do Sul. Porto Alegre: Governo do Estado do Rio Grande do Sul, Secretaria da Agricultura, 1961. 41 p.

MUELLER-DOMBAIS, D.; ELLENBERG, H. Aims and methods of vegetation ecology. New York: John Wiley e Sons, 1974. 369 p.

PAYANDEH, B. Comparison of method for assessing spatial distribuition of trees. Forest Science 16, p. 312-317. 1970.

PASTORE, U. et al. Levantamento dos recursos naturais. Folhas SH. 22. Porto Alegre e parte das folhas SH. 21 Uruguaiana e SI 22. Lagoa Mirim - Vegetação. IBGE. Rio de Janeiro: IBGE, 1986. v. 33. p. 541-619.

PIELOU, E. C. An introduction to mathematical ecology. New York: John Willey, 1969. 286 p.

RAMBO, S J. B. A fisionomia do Rio Grande do Sul. Porto Alegre: Selbach, 1956. 456 p.

RAMOS, G. Florísitca y fitosociología preliminar de la vegetación nativa leñosa de Rincón de Frabquía, Bella Unión - Uruguay. 2008. 49 f. Tesis (Tecnicatura en Gestión de Recursos Naturales y Desarrollo Sustentable) Faculdad de Ciencias, Universidad de la República, Uruguay, 2008.

REITZ, P. R.et al. Projeto Madeira do Rio Grande do Sul. Itajaí: Herbário Barbosa Rodrigues, 1983. 435 p. (Sellowia, n. 34-35).

SACHTLER, M. Inventario y desarrollo forestal del noroeste argentino (Plan NOA II). 
Reconocimiento Florestal em la Región Noroeste. Roma: FAO DP/ARG/70/536, 1977. 426 p. (Informe Técnico n. 1).

SANQUETTA, C. R. Análise da Estrutura Vertical de Florestas através do Diagrama h-M. Ciência Florestal, Santa Maria, v. 5, n. 1, p. 55-68, abr. 1995.

SILVA JUNIOR, M. C. Fitossociologia e estrutura diamétrica da mata de galeria do taquara, na Reser Ecológica do IBGE, DF. Revista Árvore, Viçosa, v. 28, n. 3, p. 419-428, 2004.

SIMAS, V. R. et al. Vegetação arbórea fanerógama ocorrente em área de nidificação de Atta vollenweideri (Forel, 1983) (Hymenoptera: formicidae). Revista da FZVA, Uruguaiana, v. 9, p. 79-88, 2002.

TEIXEIRA, A. de P.; ASSIS, M. A. Estrutura Diamétrica e Distribuição Espacial de Espécies Arbóreas em uma Mata de Brejo no Mu-nicípio de Rio Claro, SP. Revista Brasileira de Biociências, Porto Alegre, v. 5, supl. 1, p. 567-569, 2007.

VELOSO, H.; GÓES-FILHO, L. Fitogeografia brasileira: classificação fisionômica e ecológica da vegetação Neotropical. In: Projeto RADAMBRASIL. Ministério de Minas e Energia. Salvador: 1982. 85 p. (Boletim Tec. Série Vegetação, 1). 